Check for updates

Cite this: RSC Adv., 2019, 9, 28460

\title{
Novel bovine carbonic anhydrase encapsulated in a metal-organic framework: a new platform for biomimetic sequestration of $\mathrm{CO}_{2}^{\dagger}$
}

\author{
Vahideh Asadi, Reihaneh Kardanpour, Shahram Tangestaninejad, \\ Majid Moghadam, (D) Valiollah Mirkhani* and Iraj Mohammadpoor-Baltork
}

In this work, maximizing the utilization of $\mathrm{CO}_{2}$ and its precipitation as $\mathrm{CaCO}_{3}$ by using immobilized bovine carbonic anhydrase (BCA) was evaluated. In this way, selection of suitable carriers which have a gas adsorption function would enhance the $\mathrm{CO}_{2}$ sequestration efficiency of the carbonic anhydrase (CA). So a metal-organic framework (MOF), an excellent material for gas adsorption and enzyme immobilization was used. In this manner, BCA was encapsulated into the microporous zeolite imidazolate framework, ZIF-8, for the first time, using a bottle-around-a-ship method. Systematic characterization including powder X-ray diffraction (PXRD), UV-vis, and Fourier transform infrared (FT-IR) spectroscopies, BET, field emission scanning electron microscopy (FE-SEM) and energy dispersive X-ray (EDX) confirmed that the entrapment of BCA molecules was successfully achieved during the crystal growth of ZIF- 8 with an enzyme loading of ca. $100 \pm 1.2 \mathrm{mg} \mathrm{g}^{-1}$ of BCA-ZIF-8. Optimization of the matrix for increasing the stability of the enzyme in an encapsulated form is the main aim of the present study. The de novo approach was proposed because this method provides better enzyme protection from degradation, minimizes enzyme leaching and enables multiple reuse. Then, the influence of different parameters, including $\mathrm{pH}$, temperature, storage and reusability, was evaluated for enzyme@MOF composites versus free enzymes. The prepared biocatalyst exhibited outstanding activity in a wide $\mathrm{pH}$ and temperature range and demonstrates high storage stability up to 37 days. This efficient and simple association procedure seems well-adapted to produce an enzymatic bio-catalyst for biocatalytic hydration of $\mathrm{CO}_{2}$. The FT-IR analysis revealed that the structure of BCA was well maintained during the encapsulation process. The thermal stability and reusability of the BCA-ZIF- 8 increased noticeably due to the structural rigidity and confinement of the ZIF- 8 scaffolds. These two parameters are very important for practical applications.

rsc.li/rsc-advances

\section{Introduction}

Enzymes have emerged as highly efficient catalysts in environmentally friendly chemical industries. ${ }^{1,2}$ The exploration of enzymes instead of chemical catalysts in the production of pharmaceuticals and chemicals has been extensively investigated in recent years. ${ }^{3,4}$

As is well known, global warming has become one of the most urgent problems for sustainable environment. Carbon dioxide is a major contributor to greenhouse gases which cause serious climate problems. ${ }^{5}$ Therefore, several strategies, including capture and storage or conversion of $\mathrm{CO}_{2}$ into fuels and chemicals have been investigated for its reduction. Although $\mathrm{CO}_{2}$ capture by physical separation or chemical

Department of Chemistry, Catalysis Division, University of Isfahan, Isfahan 81746-73441, Iran. E-mail: stanges@sci.ui.ac.ir

$\dagger$ Electronic supplementary information (ESI) available. See DOI: $10.1039 / \mathrm{c} 9 \mathrm{ra} 04603 \mathrm{~h}$ absorption are effective, due to some limitations including generation of pollutants and high cost, the need for other capture strategies continues. ${ }^{6}$ In this way, various new approaches have been proposed. Among these methods biomimetic $\mathrm{CO}_{2}$ capture, by using $\mathrm{CA}$, is one of the most promising technologies due to a considerable cost reduction, minimal by-product generation and the green nature of the enzyme-based approaches. ${ }^{7,8}$

Carbonic anhydrase (CA, EC 4.2.1.1) is a zinc-containing metalloenzyme that rapidly catalyzes the reversible natural sequestration of $\mathrm{CO}_{2}$ which occurs rather slowly in the absence of a catalyst. ${ }^{9}$

The $\mathrm{Zn}$ active site of CA with distorted tetrahedral geometry is coordinated with three imidazole nitrogens of histidines and one oxygen from water or a hydroxyl group..$^{10}$ This water molecule has a key role for the $\mathrm{CO}_{2}$ hydration process by providing an $\mathrm{OH}^{-}$unit to convert $\mathrm{CO}_{2}$ to the hydrogen carbonate ion $\left(\mathrm{HCO}_{3}{ }^{-}\right) \cdot{ }^{11,12}$ However, application of the free enzymes has been limited, due to low operational stability and the lack of 
recyclability. Immobilization of enzymes onto suitable solid supports has been proven as an effective way for promoting the industrialization of enzymes as biocatalysts. This increases enzyme stability, handling and reusability, which in turn reduces the cost of the enzyme. ${ }^{\mathbf{1 3 , 1 4}}$ In this sense, two crucial factors need to be considered: the immobilization method and the selection of a suitable carrier. The main requirements for selection of an appropriate catalyst support are high surface area, ease of functionalization, stability, availability and biocompatibility. ${ }^{15-18}$ To-date, immobilization of enzymes on various types of materials, such as inert polymers, inorganic materials and nanoparticles has been explored extensively. ${ }^{19-22}$ Mathiowitz et al. encapsulated a model enzyme, CA, into poly(lactide-co-glycolide) microspheres $(1-3 \mu \mathrm{m})$ by a novel phase inversion technique. Lecithin was used as a surfactant in the encapsulation process. ${ }^{23}$ Also, Rayalu et al. immobilized CA in mesoporous aluminosilicate, to catalyze conversion of $\mathrm{CO}_{2}$ to $\mathrm{HCO}_{3}{ }^{-},{ }^{24}$ but the carbonation capacity of the immobilized CA was lower compared to the free enzyme. Jeong et al. immobilized CA onto gold nanoparticles assembled over amine/thiolfunctionalized mesoporous SBA-15. The synthesized biocatalyst was investigated for biocatalytic hydration of $\mathrm{CO}_{2}$ and its precipitation as $\mathrm{CaCO}_{3} \cdot{ }^{25}$ The MOFs are emerging porous materials with tunable pore size, and have shown great promise in the preparation of immobilized enzymes. ${ }^{26}$

Until now most of the MOF-enzyme preparation systems are classified into four strategies including surface adsorption, surface immobilization, diffusion into the pores (a ship-in- $a$ bottle strategy), and in situ encapsulation within the framework during the synthesis of MOF (bottle-around-a-ship approach or de novo). ${ }^{27-29}$

The surface adsorption is the most useful method, as any stable MOFs can be employed without needing to consider the dimensions of the enzyme molecules. Often, these physical interactions alone are not enough to keep the enzyme from desorbing from the support during catalysis due to relatively weak physical interactions. Furthermore, the enzymes adsorbed on the external surface of MOFs suffer inactivation caused by denaturing stresses and a hazardous external environment. ${ }^{29}$

Enzyme immobilization by covalent bonding introduces a physical barrier that will rigidify the quaternary structure of the enzyme. ${ }^{30}$ As a result, enzyme leaching will be minimized.

However by fixing the enzyme, conformational flexibility and consequently the activity of the enzyme will be decreased.

In the third route, enzymes can be physically adsorbed into the pores. As a result, enzyme stability under harsh conditions or in unnatural environments can be improved significantly due to the protection of MOFs and the reduction of the aggregation of the enzyme molecules. ${ }^{31}$

However, the enzyme encapsulation within the MOF cages requires enzyme diffusion through windows that are smaller in size than the cavity itself. The enzyme undergoes conformational changes while migrating into the MOF cavities. ${ }^{29}$

Among the previously mentioned immobilization methods, the in situ encapsulation strategy provides a better enzyme protection from degradation, minimizes enzyme leaching and excessive denaturing and enables multiple reuse. ${ }^{29}$ In this method two crucial points need to be considered: the selected MOF should be synthesized under mild conditions due to the presence of the enzyme and the synthetic MOF precursors should not have an inhibitory effect on the active site of the encapsulated enzyme.

However, despite the key advantages of the de novo approach, there are not any reports dealing with the CA encapsulation into MOFs using the ship-in-a-bottle strategy; the often large dimensions of CA might limit their diffusion through the porosity of most known stable MOFs.

Among the potential MO-based supports, zeolitic imidazolate framework-8 (ZIF-8), composed of $\mathrm{Zn}^{2+}$ ions and 2-methylimidazolate anions as a bridging linker has been primarily studied due to its important permanent porosity, high thermal and chemical stability and its ability to grow under mild conditions which is required for the preservation of the enzyme. ${ }^{32,33}$ Additionally, due to the key role of $\mathrm{Zn}$ for the transformation of $\mathrm{CO}_{2}$ into carbonate, herein ZIF-8 was chosen on the basis of the structural similarity between the $\mathrm{Zn}$ coordination in this MOF and the CA active center. On the other hand, it is important that the nodes of the selected MOF should not have an inhibitory effect on the $\mathrm{Zn}$ active site of CA. Therefore, after careful evaluation of the inhibitory effect of different $\mathrm{Zn}$ compounds on the $\mathrm{Zn}$ active site of $\mathrm{CA}, \mathrm{Zn}\left(\mathrm{ClO}_{4}\right)_{2}$ was selected as the precursor for the synthesis of ZIF-8. ${ }^{34,35}$

Previously, pure ZIF-8 was applied to carry out the capture of $\mathrm{CO}_{2}$ due to its sodalite structure, large surface area and the kinetic diameter, but its adsorption efficiency for $\mathrm{CO}_{2}$ was not desirable. ${ }^{36,37}$

The CA, like most of the enzymes, is a macromolecule with large dimensions of 3 to $5 \mathrm{~nm} .^{38}$

Cui et al. successfully designed a combined immobilization system of CA and ZIF-8 by the physical adsorption of CA onto the external surface of ZIF-8. ${ }^{39}$ The synthesized composite was utilized as a robust biocatalyst for the sequestration of $\mathrm{CO}_{2}$, but this immobilized system suffered from problems of weak interactions such as lower enzyme protection associated with high enzyme exposure to the environment, as well as a significantly higher enzyme leaching and detachment of the enzyme during the process. Chen et al. embedded the CA enzyme into a zeolitic imidazolate framework (ZIF-L) of nanoparticles to synthesize CA/ZIF-L composite. ${ }^{40}$ However, it was difficult to recover due to their nanometer size, and easy to damage due to the low mechanical strength during the stirring process. Cui et al. embedded CA molecules into MOFs via co-precipitation and then immobilized the prepared composites into PVA-chitosan (PVA-CS) hydrogels to gain the PVA/CS/CA@ZIF-8 hydrogel membrane with an improved $\mathrm{CO}_{2}$ capture capacity. ${ }^{\mathbf{4 1}}$

Three analogous families of CAs exist within nature: $\alpha$-CAs (predominant within animals), $\beta$-CAs (predominant within plants), and the $\gamma$-CAs (predominant within Archaea). ${ }^{42}$ After investigation of their inhibitory effects BCA was selected because the imidazole group in the ZIF-8 structure has no effect on the high activity of the BCA. ${ }^{43}$

Considering that the six-ring pores of the ZIF-8 are not accessible for entering the BCA, here a pre-synthetic strategy was utilized, using simple and totally green synthetic conditions 
[aqueous solution at room temperature (RT)] by incorporating a BCA solution into the initial reaction mixture. In fact, the high chemical and structural stability of the ZIF-8 scaffolds can offer a protective effect for the encapsulated enzyme which prevents the enzyme leaching or enzyme agglomeration, and at the same time allows the transfer of small-molecules of substrates or products.

To this end, in continuation of a recently published paper on the synthesis of the lipase@ZIF-67 biocomposite, ${ }^{44}$ the de novo approach was selected, because it allows suitable protection of the enzyme to avoid leaching. On the other hand, this method makes it possible to entrap enzymes with larger dimensions than the MOF pore size.

The resulting nanobiocomposite denoted as BCA-ZIF-8 was fully characterized by UV-vis and Fourier transform infrared (FT-IR) spectroscopies, powder X-ray diffraction (PXRD), FESEM, BET and EDX. Finally, the activity of the prepared biocomposite in the biocatalytic hydration of $\mathrm{CO}_{2}$ and its precipitation as $\mathrm{CaCO}_{3}$ was demonstrated (Scheme 1).

\section{Experimental}

\section{Materials}

Bovine carbonic anhydrase (BCA, lyophilized powder), 2-methylimidazole (2-mim, 98\%), zinc perchlorate hexahydrate
$\left[\mathrm{Zn}\left(\mathrm{ClO}_{4}\right)_{2} \cdot 6 \mathrm{H}_{2} \mathrm{O}\right], \quad$ triethylamine (TEA), 2-amino-2(hydroxymethyl)-1,3-propanediol (Tris base), $p$-nitrophenol ( $p$ $\mathrm{NP}), p$-nitrophenyl acetate ( $p$-NPA), anhydrous calcium chloride $\left(\mathrm{CaCl}_{2}\right)$, and protein assay reagents for producing the Bradford reagent were purchased from Aldrich and used without purification. Other reagents were purchased from Merck or Fluka as ACS reagent grade chemicals. All solutions were prepared with deionized water.

\section{Characterization}

The PXRD analysis was carried out on a Bruker D8 Advance instrument using $\mathrm{Cu} \mathrm{K}_{\alpha}(\lambda=1.5406 \AA)$ radiation at $2 \theta: 5^{\circ}$ to $35^{\circ}$. Specific surface area, pore volume and pore size were measured by $\mathrm{N}_{2}$ adsorption-desorption at $77.360 \mathrm{~K}$ using a Micrometrics ASAP 2000 instrument. Before each measurement, samples were activated via supercritical $\mathrm{CO}_{2}$ drying or outgassing at room temperature for $3 \mathrm{~h}$ under vacuum conditions. Infrared spectra were collected in the range $400-4000 \mathrm{~cm}^{-1}$ on a JASCO 6300D instrument.

Thermogravimetric analyses (TGA) were performed on a PerkinElmer STA 6000 thermal analyzer. For this purpose, $c a$. $20 \mathrm{mg}$ of sample was placed into an alumina crucible and heated in a continuous-flow of $\mathrm{N}_{2}$ with a heating ramp rate of $20{ }^{\circ} \mathrm{C} \min ^{-1}$ from $30{ }^{\circ} \mathrm{C}$ to $900{ }^{\circ} \mathrm{C}$. The scanning electron

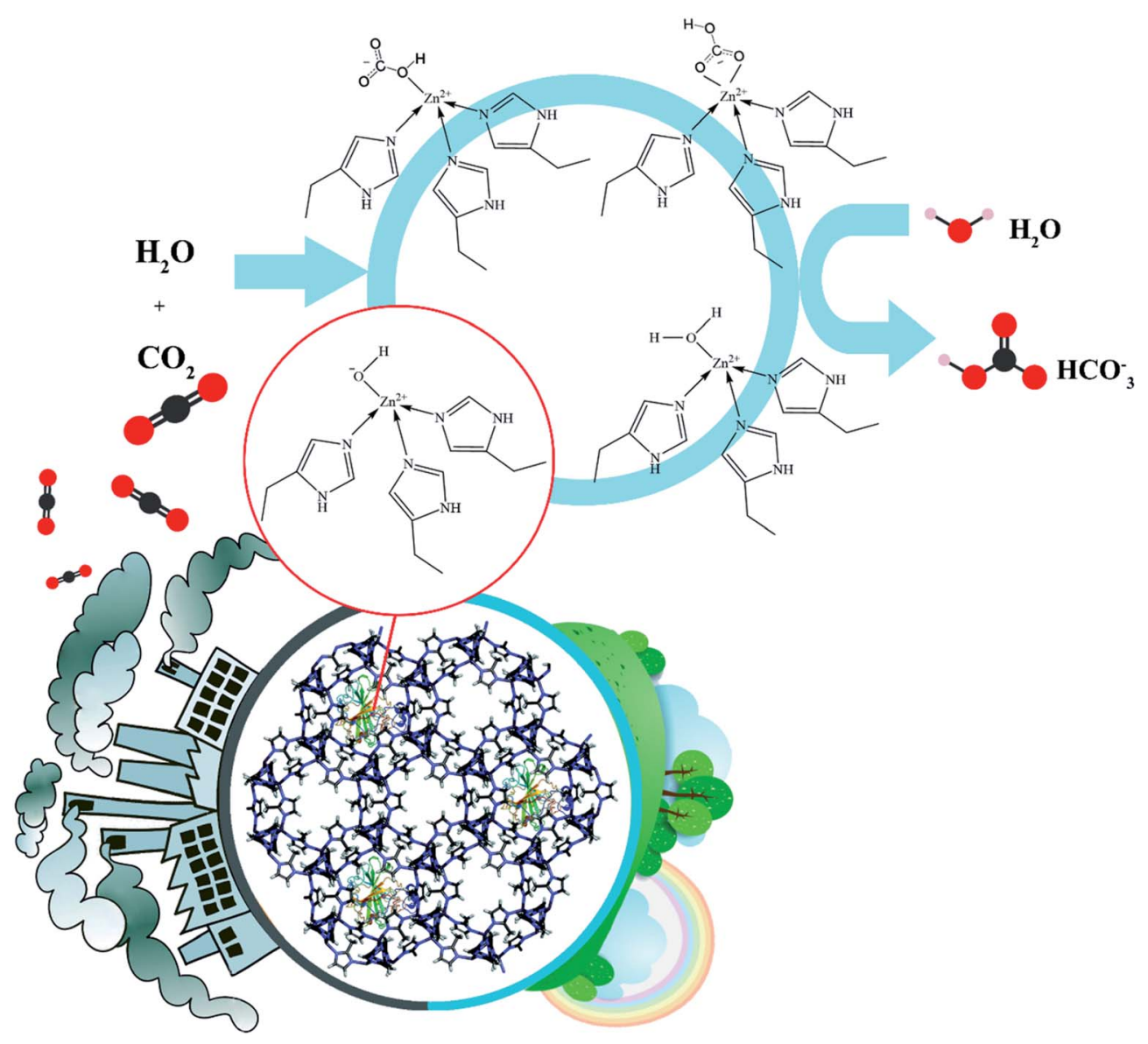

Scheme 1 Utilization of BCA-ZIF-8 biocomposite in the biocatalytic hydration of $\mathrm{CO}_{2}$. 
micrographs were taken on a Hitachi S-4700 FE-SEM. The UVvis spectra were recorded on a JASCO V-570 spectrophotometer.

\section{Preparation}

The BCA encapsulation in the ZIF-8 composite was achieved by mixing $5 \mathrm{~mL}$ of BCA solution $\left(2 \mathrm{mg} \mathrm{mL}^{-1}\right.$ in $50 \mathrm{mM}$ Tris buffer, $\mathrm{pH}$ 8.0) and 2-methylimidazole $\left(80.0 \mathrm{mg} \mathrm{mL}{ }^{-1}\right)$ and $\mathrm{ZnClO}_{4}^{-}$ $\cdot 6 \mathrm{H}_{2} \mathrm{O}\left(126.6 \mathrm{mg} \mathrm{mL}^{-1}\right)$ aqueous solutions (Scheme 2). In the next step, $0.3 \mathrm{~mL}$ of TEA was added to the above mixture. After stirring for about $1 \mathrm{~h}$, the product was collected by centrifugation at $6000 \mathrm{rpm}$ for $20 \mathrm{~min}$ and washed three times with Tris buffer and de-ionized water.

\section{Protein concentration determination and immobilization efficiency}

The amount of BCA in the enzyme solution before and after immobilization was determined using the Bradford method (Fig. S1, ESI $\dagger$ ). ${ }^{45}$ The enzyme encapsulation efficiency was determined by the following formula (eqn (1)): ${ }^{46}$

$$
\text { Enzyme encapsulation efficiency } \begin{aligned}
(\%)= & \left(C_{1} V_{1}-C_{2} V_{2}\right) \\
& \times 100 /\left(C_{1} V_{1}\right)
\end{aligned}
$$

where $C_{1}$ and $C_{2}$ are the initial and final enzyme concentrations, respectively, and $V_{1}$ and $V_{2}$ correspond to the volumes of the enzyme solution used for encapsulation and the supernatant after encapsulation, respectively.

\section{Encapsulation and activity detection}

The CA catalyzed hydrolysis of $p$-NPA exhibits certain similarities with the enzymatically catalyzed hydration of $\mathrm{CO}_{2}$ and of acetaldehyde. Thus, the $\mathrm{pH}$ rate profile for CA catalyzed hydrolysis of $p$-NPA has an analogous sigmoid shape to that observed in the reversible hydration of $\mathrm{CO}_{2}$ and of acetaldehyde. ${ }^{34}$ These catalytic properties occur at the same active site as the hydration of $\mathrm{CO}_{2}$. In order to investigate a mimic reaction for the $\mathrm{CO}_{2}$ hydration activity, the $p$-NPA assay was used to monitor the activity of $\mathrm{CA}$ which exhibited a high level of correlation with the $\mathrm{CO}_{2}$ hydration activity. ${ }^{47}$ The enzyme activity of the free and immobilized BCA was measured at RT by

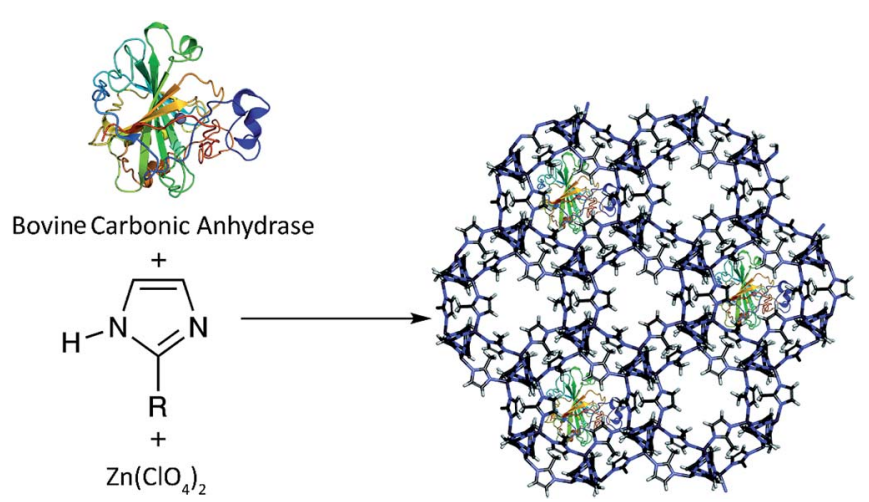

Scheme 2 Schematic representation of the preparation of the BCAZIF-8 biocomposite. monitoring the increase in the absorption band at $405 \mathrm{~nm}$, which was promoted by the hydrolysis of $p$-NPA to $p$-NP. ${ }^{48}$ The assay mixture consisting of $0.8 \mathrm{~mL}$ Tris buffer ( $50 \mathrm{mM}, \mathrm{pH} 8.0$ ), $0.1 \mathrm{~mL}$ substrate solution, different concentrations of $p$-NPA $(0.5,1,1.5,2,2.5 \mathrm{mM})$ dissolved in acetonitrile, and $0.1 \mathrm{~mL}$ of enzyme solution, was mixed in a $1 \mathrm{~mL}$ cuvette using a micropipette. The enzyme activity was measured with a UV-vis spectrophotometer by varying the concentration of substrate for $5 \mathrm{~min}$ at $1 \mathrm{~min}$ intervals. Blank experiments were also conducted in the absence of the catalyst to estimate the selfdissociation of $p$-NPA in each assay solution. The catalytic activity of the immobilized BCA was estimated using a similar procedure as described previously. The relative activity was defined as the percentage of the free CA activity used for BCAZIF-8 production compared to the biocatalyst activity. The activity of free and encapsulated enzyme is shown in Table 2.

\section{Effect of $\mathbf{p H}$}

In order to investigate the optimum $\mathrm{pH}$ value, the free and encapsulated BCA were incubated in Tris buffer solution (50 $\mathrm{mM}$ ) in the $\mathrm{pH}$ range of 6-10 at RT. After $1 \mathrm{~h}$, the residual activities of the free and encapsulated enzyme were determined as described previously.

\section{Thermal stability}

The thermal stability of the free and encapsulated BCA was determined by incubating them in $50 \mathrm{mM}$ Tris buffer at $\mathrm{pH}=8$ in the temperature range of $30-70{ }^{\circ} \mathrm{C}$ for $1 \mathrm{~h}$. Afterwards, the relative activities were calculated as mentioned previously.

\section{The $\mathrm{CO}_{2}$ sequestration and evaluation of $\mathrm{CaCO}_{3}$}

Generally, hydration of $\mathrm{CO}_{2}$ and its subsequent sequestration as $\mathrm{CaCO}_{3}$ in the presence of free and encapsulated BCA was performed as follows: initially, $\mathrm{CO}_{2}$ gas was introduced into $20 \mathrm{~mL}$ of deionized water at a constant flow rate for $30 \mathrm{~min}$. Then, $3 \mathrm{mg}$ of free BCA was added to a $10 \mathrm{~mL}$ Tris buffer solution $(\mathrm{pH}=8.0)$ at a fixed optimum temperature of $25{ }^{\circ} \mathrm{C}$. The enzyme containing solution was added to the $\mathrm{CO}_{2}$ solution and the mixture was continuously stirred for about $30 \mathrm{~min}$. The hydrated $\mathrm{CO}_{2}$ solution was filtered and subsequently $0.9 \mathrm{~g}$ of $\mathrm{CaCl}_{2} \cdot 2 \mathrm{H}_{2} \mathrm{O}$ was added. The resulting $\mathrm{CaCO}_{3}$ was filtered and weighed after drying. Finally, the previously used procedure for the encapsulated enzyme was applied. In this manner, $30 \mathrm{mg}$ of the prepared biocatalyst was utilized to maintain the BCA concentration.

\section{Reuse of the bio-catalyst}

In order to investigate the reusability, after each run the prepared composite was separated and washed thoroughly with Tris buffer and finally, the enzyme activity of the immobilized BCA was measured at room temperature by monitoring the increase in the absorption band at $405 \mathrm{~nm}$, which was promoted by the hydrolysis of $p$-NPA as described for the activity detection. 


\section{Recycling of the bio-catalyst}

The recyclability of the BCA-ZIF-8 biocatalyst was evaluated after the sequential $\mathrm{CO}_{2}$ sequestration. In this way, upon completion of one cycle, the prepared biocatalyst was recovered and washed with Tris buffer and dispersed in a fresh reaction mixture to carry out the next cycle. The structure of the recovered biocatalyst was monitored by PXRD and FT-IR after the last cycle (Fig. 1 and 2).

\section{Results and discussion}

\section{Preparation and characterization of the bio-catalyst}

The CA (molecular weight of approximately $30 \mathrm{kDa}$ and dimensions of $5 \times 4.2 \times 3.3 \mathrm{~nm}^{3}$ ) is known as the fastest enzyme for catalyzing the conversion of one million $\mathrm{CO}_{2}$ molecules to bicarbonate per second. ${ }^{38}$ Due to significant drawbacks with the application of free enzymes for large-scale industrial processes such as solubility and recovery problems, several immobilization techniques for CA have been proposed in recent years.

On the other hand, zeolitic imidazolate frameworks (ZIFs), a prototypical structure of zeolites, have attracted great attention due to their important permanent porosity, low density and high thermal and moisture stability. ${ }^{49}$ The ZIF-8, synthesized by the mixing of zinc nitrate $\left[\mathrm{Zn}\left(\mathrm{NO}_{3}\right)_{2}\right]$ and 2-methylimidazolate, was initially prepared by Pan et al. via a simple RT method. ${ }^{50}$ The ZIF-8 exhibits a cubic structure based on a space-filling packing of regular truncated octahedrals. Due to the small cages and narrow six-ring pore of ZIF-8, here a pre-synthetic strategy was utilized by incorporating a CA solution into the initial reaction mixture. It should be noted that after careful evaluation of the inhibitory effect of different zinc compounds on the enzyme activity, $\mathrm{Zn}\left(\mathrm{ClO}_{4}\right)_{2}$ was selected as the precursor for the synthesis of ZIF-8. ${ }^{34,35}$

The resulting nanobiocomposite was fully characterized by different methods. The PXRD patterns of the BCA-ZIF-8 composite with intensities and peak positions at $2 \theta$ of $7.3^{\circ}$, $10.45^{\circ}, 11.5^{\circ}, 12.7^{\circ}, 14.8^{\circ}, 16.4^{\circ}, 17.95^{\circ}$, and $22^{\circ}$ agreed well with the patterns of the pure ZIF-8 (Fig. 1), clearly indicating that the incorporation of the enzyme did not affect the crystal structure of ZIF-8. ${ }^{51}$

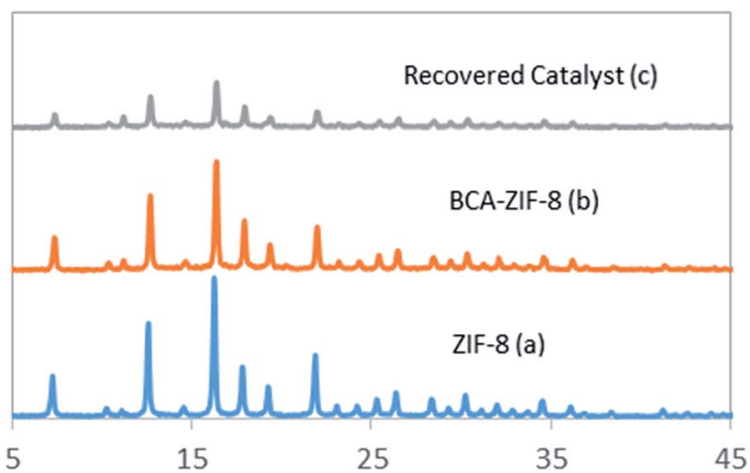

Fig. 1 The PXRD patterns of ZIF-8 (a), BCA-ZIF- 8 (b) and recovered BCA-ZIF-8 (c).

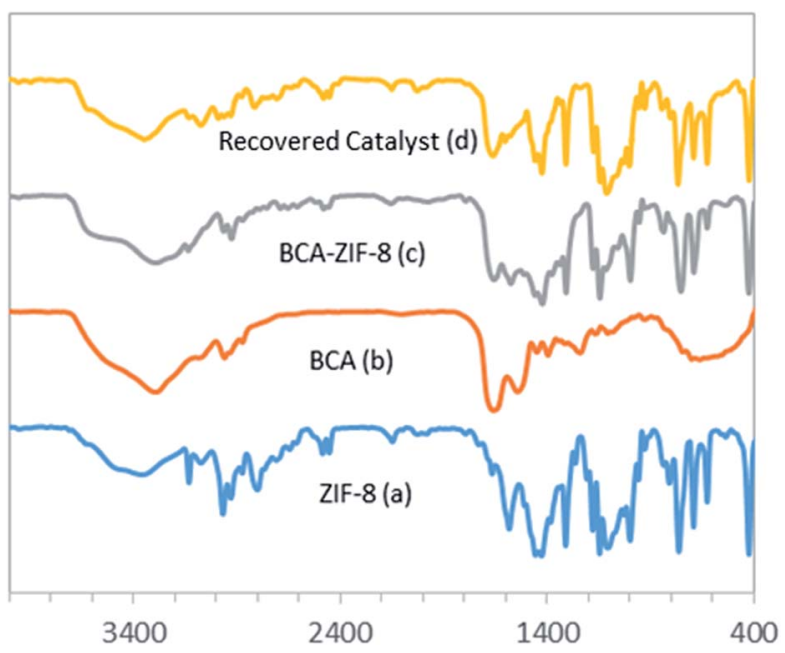

Fig. 2 The FT-IR spectra of ZIF-8 (a), free BCA (b), BCA-ZIF-8 composite (c) and recovered BCA-ZIF-8 (d).

Fig. 2 shows the FT-IR spectra of ZIF-8, BCA and the prepared biocatalyst. The vibrational bands in the range of 600$1500 \mathrm{~cm}^{-1}$ correspond to the characteristic stretching and bending modes of the imidazole ring (Fig. 2a). ${ }^{52}$ Also, the band at $1580 \mathrm{~cm}^{-1}$ is ascribed to the stretching mode of $\mathrm{C}=\mathrm{N}$ in 2mim, whereas the bands at 2927 and $3131 \mathrm{~cm}^{-1}$ can be related to the stretching mode of $\mathrm{C}-\mathrm{H}$ of the aromatic ring and the aliphatic chain of 2-mim, respectively. Also, the band at $420 \mathrm{~cm}^{-1}$ represents the $\mathrm{Zn}-\mathrm{N}$ stretching, which corresponds to the bonding between the $\mathrm{Zn}^{2+}$ cations and 2-mim to form imidazolate. $^{53}$

As shown in Fig. 2c, all of the previous bands are well maintained in the biocatalyst spectrum. Additionally, the existence of the band at $1648 \mathrm{~cm}^{-1}$ corresponding to double bonds and $\mathrm{C}=\mathrm{O}$ stretching modes of the enzyme verified the presence of the protein in the composites. ${ }^{39}$ Moreover, the free BCA spectrum exhibited stretching bands at $1500-1550 \mathrm{~cm}^{-1}$ corresponding to amide II bonds and $\mathrm{NH}$ stretching vibration which were visible in the biocatalyst spectrum, confirming the presence of the CA within the ZIF-8 (Fig. 2c). ${ }^{53}$

The FE-SEM images in Fig. 3 clearly show that the morphology of the ZIF-8 was unaffected during the encapsulation of BCA. In addition, the EDX results, obtained from the
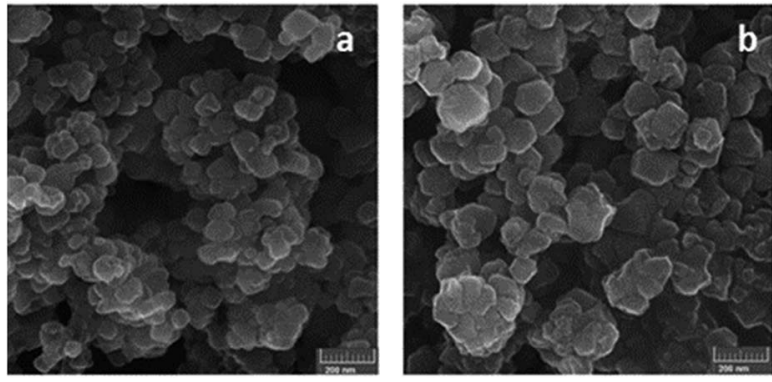

Fig. 3 The FE-SEM images of (a) pure ZIF-8, (b) BCA-ZIF-8. 
SEM analysis for the BCA-ZIF-8 composite (Fig. S2, ESI $\dagger$ ) clearly show the presence of $\mathrm{Zn}$ and $\mathrm{S}$.

The effective surfaces and porosity of both the ZIF-8 and the biocatalyst were determined using $\mathrm{N}_{2}$ physisorption measurements at $77 \mathrm{~K}$ (Fig. 4), and the textural parameters are presented in Table 1. These results indicate a noticeable decrease in BET surface area and total pore volume of ZIF-8 after encapsulation of BCA from 331 to $125 \mathrm{~m}^{2} \mathrm{~g}^{-1}$ and from 0.29 to $0.16 \mathrm{~cm}^{3} \mathrm{~g}^{-1}$, respectively. This is in agreement with the partial occupation of the parent framework by enzyme groups. It should be noted that both ZIF-8 and BCA-ZIF-8 are classified as mesopore materials $(2-5 \mathrm{~nm})$. Additionally, the average pore size of ZIF-8 increased from 3.58 to $5.12 \mathrm{~nm}$ after encapsulation. This agrees well with the diameter of the encapsulated enzyme. ${ }^{38}$

The TGA curves provide information on the thermal stability of ZIF-8 and BCA-ZIF-8 (Fig. 5). The TGA curve of ZIF-8 and BCA-ZIF-8 show an initial weight loss related to the removal of guest water molecules and residual imidazole in the pores within the range of $20-200{ }^{\circ} \mathrm{C}$, followed by the next weight loss in the range of $200-300{ }^{\circ} \mathrm{C}$ attributed to the loss of the BCA enzyme. ${ }^{39}$ By comparison of step two in the TGA curves of BCAZIF-8 and ZIF-8, it can be seen that the weight loss of BCA-ZIF-8 is larger than that of pure ZIF-8 which proves the claim about the presence of BCA in the framework.

The UV-vis measurements of the prepared composite give an additional indication for the presence of BCA in the ZIF-8 framework as seen in Fig. 6. In addition to the absorption bands corresponding to the ZIF-8 support, an extra absorption band around $286 \mathrm{~nm}$ was attributed to the BCA encapsulated in the framework (Fig. 6b). ${ }^{54}$

\section{Catalytic experiments}

The catalytic activity of the BCA-ZIF-8 composite was first investigated with the hydrolysis of $p$-NPA into $p$-NP as a function of the reaction conditions $(\mathrm{pH}$, temperature, presence of precursors of MOF, reusability and storage) based on the procedure described before. In this manner, the hydrolysis of $p$ NPA was followed spectrophotometrically by observing the formation of the $p$-nitrophenolate and acetic acid. The reaction is described in Fig. S3 (ESI $\dagger$ ).

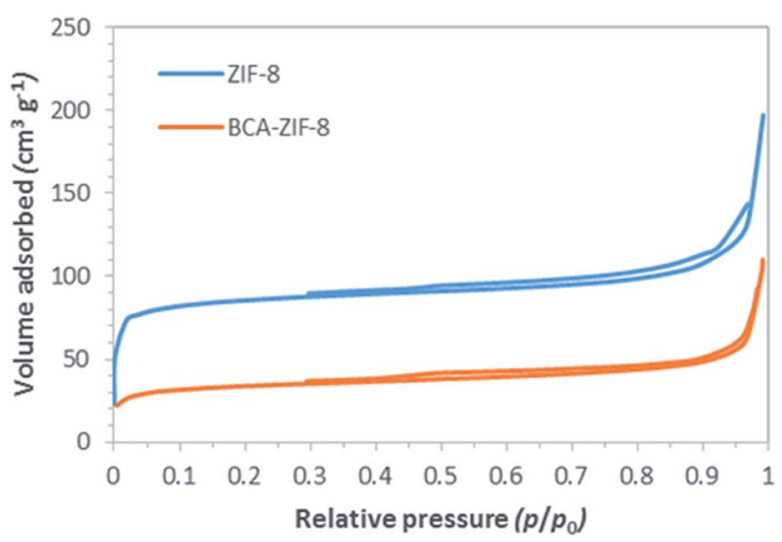

Fig. 4 The $\mathrm{N}_{2}$ adsorption isotherms of ZIF- 8 and BCA-ZIF- 8 at $77 \mathrm{~K}$.
Table 1 The BET results of the BCA-ZIF- 8 catalyst

\begin{tabular}{llll}
\hline Samples & $S_{\text {BET }}\left(\mathrm{m}^{2} \mathrm{~g}^{-1}\right)$ & $\begin{array}{l}\text { Total pore volume } \\
\left(\mathrm{cm}^{3} \mathrm{~g}^{-1}\right)\end{array}$ & $\begin{array}{l}\text { Total pore diameter } \\
(\mathrm{nm})\end{array}$ \\
\hline ZIF-8 & 331 & 0.29 & 3.58 \\
BCA-ZIF-8 & 125 & 0.16 & 5.12 \\
\hline
\end{tabular}

\section{The kinetic parameters}

The kinetic parameters for the hydrolysis of $p$-NPA were estimated using the Michaelis-Menten and Lineweaver-Burk equations (eqn (3) and (4)).

According to the Michaelis-Menten kinetic model, an initial reaction between the substrate (S) and enzyme (E) occurs to form an enzyme-substrate (ES) complex and then product formation occurs regenerating the enzyme in the process:

$$
\mathrm{E}+\mathrm{S} \leftrightarrow \mathrm{ES} \rightarrow \mathrm{E}+\mathrm{P}
$$

Both free and encapsulated enzyme activities were determined at RT in $50 \mathrm{mM}$ Tris-buffer at $\mathrm{pH}$ 8.0. The graphs were plotted using different substrate concentrations and their corresponding reaction rates. The reciprocal of substrate concentration $(1 / S)$ was plotted against the reciprocal of reaction rate $(1 / V)$ according to the following equations:

$$
\begin{gathered}
V=\frac{k_{\mathrm{cat}}[\mathrm{S}]\left[\mathrm{E}_{0}\right]}{K_{\mathrm{m}}+[\mathrm{S}]} \\
\frac{1}{V}=\frac{1}{V_{\max }}+\frac{K_{\mathrm{m}}}{V_{\max }} \frac{1}{[\mathrm{~S}]}
\end{gathered}
$$

where $V$ is the rate of $p$-NP formation, $V_{\max }$ is the maximum rate, $k_{\text {cat }}$ is the catalytic rate constant, $\left[\mathrm{E}_{0}\right]$ is the enzyme concentration, [S] is the substrate concentration, $K_{\mathrm{m}}$ is the substrate concentration when the rate is equal to $V_{\max } / 2$, which also shows the affinity of the enzyme for the substrate, and $k_{\text {cat }} / K_{\mathrm{m}}$ is the kinetic constant. The results are shown in Table 2.

\section{Effect of synthetic MOF precursors (2-methylimidazol and zinc nitrate) on the CA activity}

In order to investigate whether the catalytic activity of the BCA enzyme is affected by the synthetic MOF precursors, the

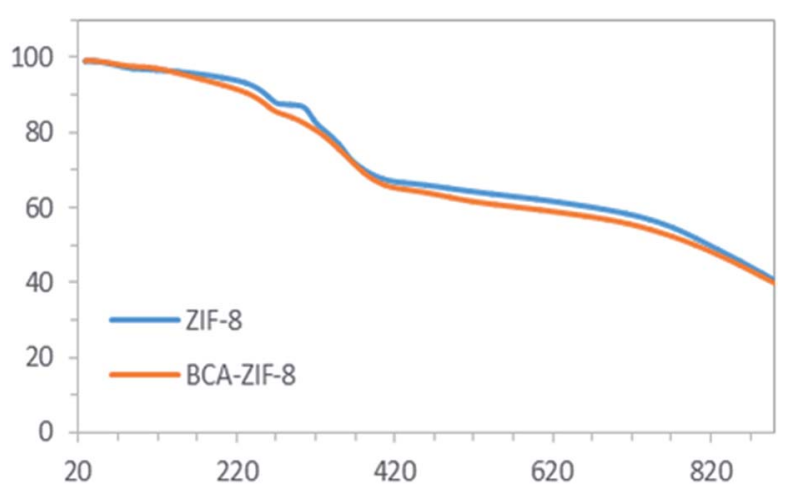

Fig. 5 The TGA curves of ZIF-8 and the BCA-ZIF-8 composite. 


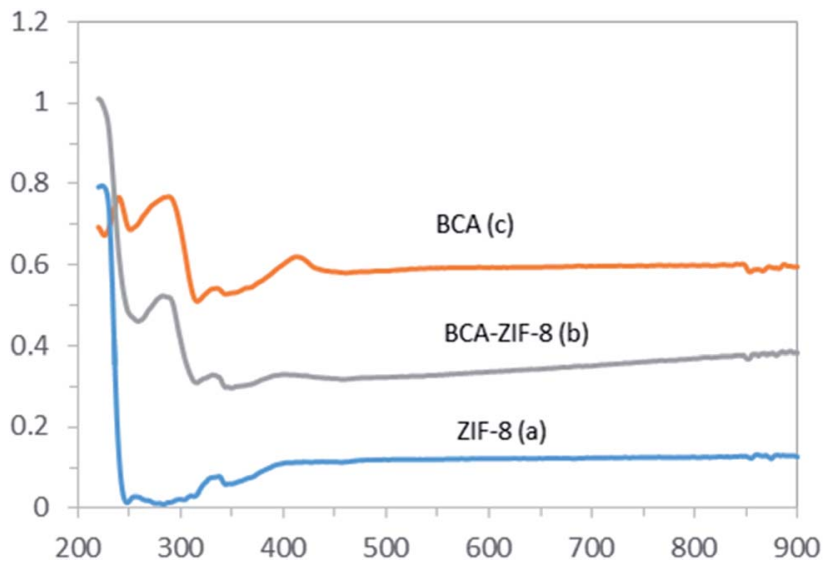

Fig. 6 The UV-vis spectra of ZIF-8 (a), BCA-ZIF-8 (b) and BCA (c).

Table 2 Kinetic parameters, relative activity

\begin{tabular}{lllll}
\hline Samples & $V_{\max }\left(\mu \mathrm{M} \mathrm{min}^{-1}\right)$ & $K_{\mathrm{m}}(\mathrm{mM})$ & $k_{\text {cat }} / K_{\mathrm{m}}\left(\mathrm{M}^{-1} \mathrm{~s}^{-1}\right)$ & Activity (\%) \\
\hline BCA & 42.7 & 8.9 & 399.8 & 100 \\
BCA-ZIF-8 & 54.36 & 6.4 & 471.8 & 118 \\
\hline
\end{tabular}

enzymatic activity of free BCA was assessed by adding $\mathrm{NO}_{3}{ }^{-}$ ions, 2-mim and TEA to the reaction medium as shown in Table 3. Due to similarity between the active center site of the BCA enzyme and the ZIF-8 nodes, the Zn ion could not have an inhibitory effect on the activity of the enzyme. The activity of the free enzyme in the presence of 2-mim and TEA was not affected, and interestingly, increased. But the $\mathrm{NO}_{3}{ }^{-}$counter ion of $\mathrm{Zn}^{2+}$ decreased the activity of BCA, therefore $\mathrm{Zn}\left(\mathrm{ClO}_{4}\right)_{2}$ was utilized as the precursor for the synthesis of ZIF-8.

\section{Effect of pH}

As shown in Fig. $7 \mathrm{~b}$, the effect of $\mathrm{pH}$ on the relative activity of both the free and encapsulated BCA was evaluated in the $\mathrm{pH}$ range of 6.0-10. The relative activity of the free and encapsulated BCA showed a considerable difference within the $\mathrm{pH}$ range of 6-8. It is worth mentioning that encapsulated BCA exhibited a higher tolerance in the acidic regions compared to the free enzyme. Generally, the encapsulation method seemed to enhance the tolerance of the enzyme to harsh conditions.

\section{Thermal stability}

The thermal stability of the biocatalyst was a critical point to be considered for industrial purposes. It has a very important effect on the conformational transitions of the enzyme at high temperatures which can lead to a loss of catalytic activity. Therefore, immobilization of the enzyme into suitable carriers might improve the thermal stability of the biocatalyst.

Thus, the relative activity of free and encapsulated BCA was investigated as a function of temperature in the range of 25 to $65{ }^{\circ} \mathrm{C}$ (Fig. 7c). As can be seen, the maximum activity for BCA was at $35{ }^{\circ} \mathrm{C}$. It is worth mentioning that encapsulated BCA exhibited a higher activity in all the temperatures evaluated (up to $65{ }^{\circ} \mathrm{C}$ ), compared to its free counterpart. For instance, at $55{ }^{\circ} \mathrm{C}$, the decrease in activity of the encapsulated BCA was only $14 \%$, whereas the decrease in activity of free enzyme was $45 \%$ of its initial activity. These results clearly confirmed that the encapsulation of the BCA enzyme into MOFs can prevent its conformation transition at high temperatures and increase its thermal stability.

By further increasing the temperature, a drop in enzyme activity was observed which was again slower in the case of the encapsulated enzyme. This decrease was due to denaturation of the enzyme which occurred at high temperatures.

\section{Storage stability}

To see if the encapsulation provided an adequate environment for the storage stability of the enzyme, the activity of free and encapsulated enzyme in Tris buffer ( $50 \mathrm{mM}, \mathrm{pH} 8.0)$ was followed for 37 days at RT. As shown in Fig. 7a, the decreased activity of the encapsulated BCA was only $11 \%$ whereas the decreased activity of the free BCA was $53 \%$ of its initial activity up to 37 days.

\section{Reusability}

The reusability of the enzyme is a crucial point that needs to be considered for practical use. Especially, because this parameter is one of the main requirements for utilization of the biocatalysts for the capture of $\mathrm{CO}_{2}$. Fig. 8a represents 12 cycles of hydrolysis of $p$-NPA by BCA-ZIF-8. After each run the prepared composite was separated and washed thoroughly with Tris buffer and finally immersed into fresh substrate for the next run. The results demonstrated that the activity of the BCA-ZIF-8 composite retained nearly $100 \%$ of its initial activity for up to eight cycles and maintained about $84 \%$ of its initial activity after 12 cycles.

Table 3 Activity of $\mathrm{BCA}$ in the presence of $\mathrm{NO}_{3}$ ions, $\mathrm{ClO}_{4}$ ions, TEA and 2-mim

\begin{tabular}{llrr}
\hline Precursors & Concentration & Activity of BCA $\left(\mu \mathrm{M} \mathrm{min}^{-1} \mathrm{mg}^{-1}\right.$ enzyme $)$ & 100 \\
\hline BCA & $0.3 \mathrm{mg} \mathrm{mL}$ & 168 & 6 \\
$\mathrm{Zn}\left(\mathrm{NO}_{3}\right)_{2}$ & $0.11 \mathrm{M}$ & 10 & 80 \\
$\mathrm{Zn}\left(\mathrm{ClO}_{4}\right)_{2}$ & $0.04 \mathrm{M}$ & 135 & 274 \\
$2-\mathrm{mim}$ & $0.65 \mathrm{M}$ & 460 & 90 \\
TEA & $0.24 \mathrm{M}$ & 150 &
\end{tabular}



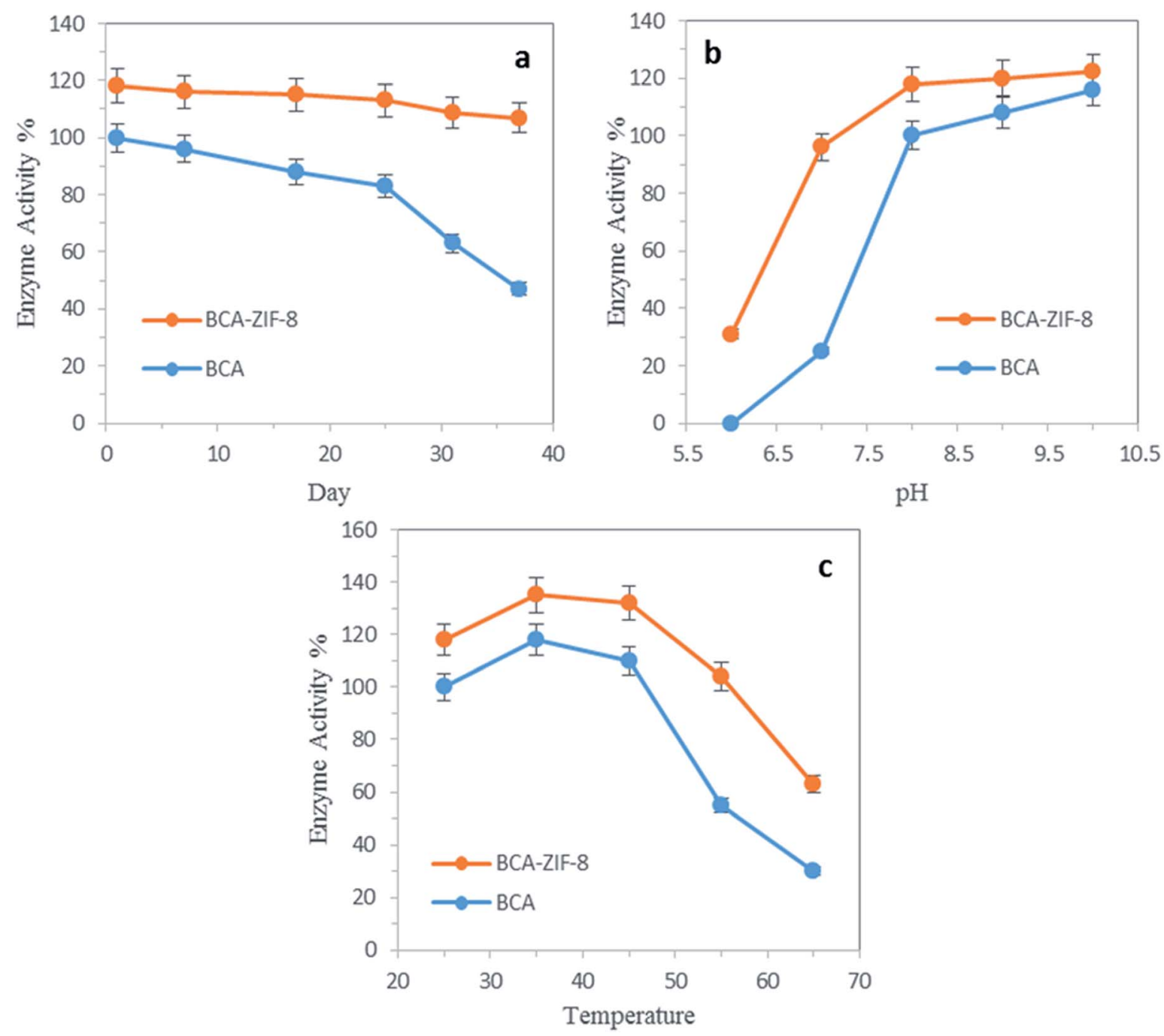

Fig. 7 (a) Storage stability, and (b) effect of $\mathrm{pH}$ and (c) temperature on the enzyme activity.

Additionally, the amount of BCA in the enzyme solution after the recycling test was determined using the Bradford method. The leaching of the BCA enzyme was not detected during the stability assay. Therefore, the synthesized biocatalyst can be considered as a reusable sorbent for $\mathrm{CO}_{2}$ capture and has potential for industrial applications.
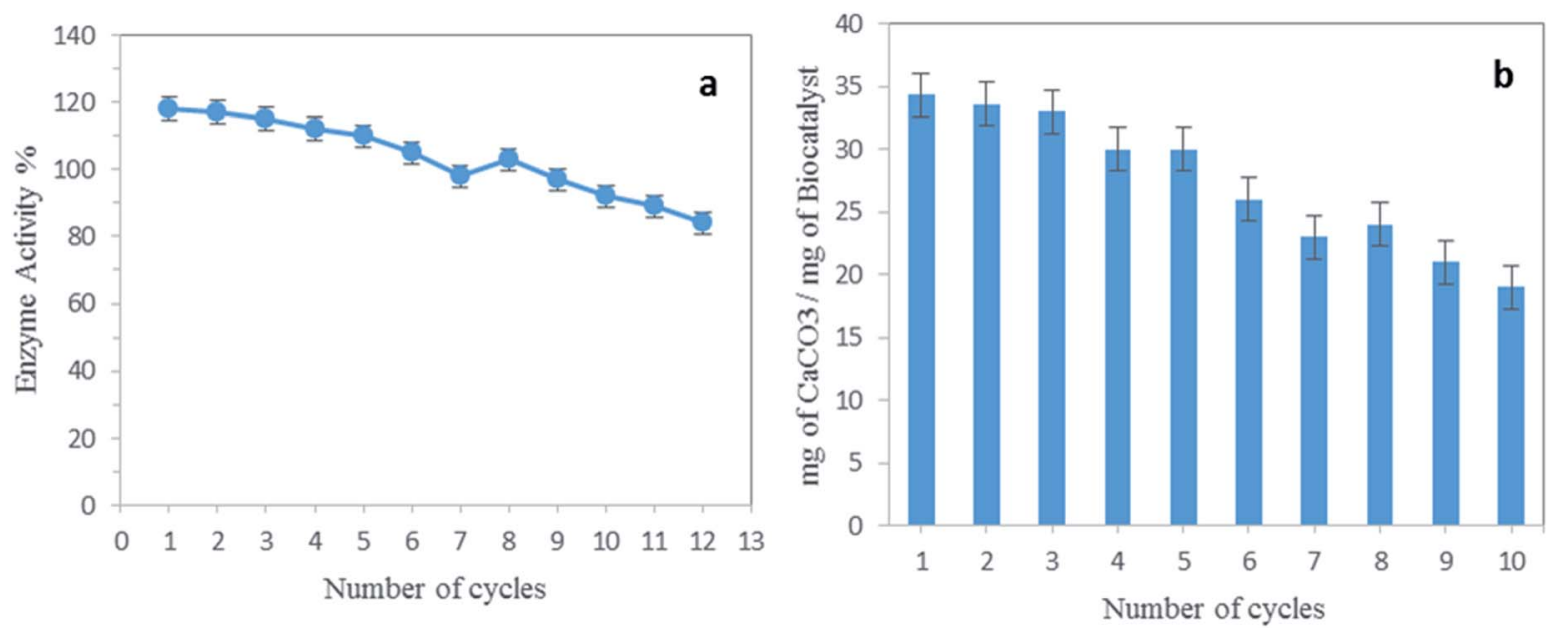

Fig. 8 (a) Reusability and (b) recyclability of the biocatalyst. 
The obtained results proved the claim that the de novo strategy prevented the enzyme leaching or enzyme agglomeration and as a result showed a more advanced performance than other preparation strategies.

\section{Recyclability}

Fig. 8b illustrates the 10 cycles of $\mathrm{CaCO}_{3}$ precipitation. The $\mathrm{CO}_{2}$ sequestration capacity based on the conversion of $\mathrm{CO}_{2}$ to $\mathrm{CaCO}_{3}$ was quantified. As can be seen, the amount of the resulting $\mathrm{CaCO}_{3}$ was still noticeable.

\section{Catalytic mechanism of BCA and BCA-ZIF-8}

In this work, the conversion of $\mathrm{CO}_{2}$ into $\mathrm{CaCO}_{3}$ was performed in the presence of BCA-ZIF-8 to explore the capture capacity of the prepared biocatalyst.

The CA, as one of the most representative enzymes containing $\mathrm{Zn}^{2+}$, is frequently used for catalyzing the conversion of $\mathrm{CO}_{2}$ molecules to bicarbonate.

Due to the synergistic interaction between the BCA enzyme and the ZIF-8 support it was expected that the yields of solid $\mathrm{CaCO}_{3}$ produced by the BCA-ZIF- 8 composite would be more than with the free BCA. In fact, under humidified conditions, the imidazole group ( $\mathrm{mIm}$ ) present in ZIF-8, could participate in the hydration of $\mathrm{CO}_{2}$ and formation of bicarbonate $\left(\mathrm{HCO}_{3}{ }^{-}\right)$due to its nucleophilic character. ${ }^{54,55}$

The reaction can be expressed as:

$$
\mathrm{H}_{2} \mathrm{O}+\mathrm{mIm}+\mathrm{CO}_{2} \Leftrightarrow \mathrm{mIm}^{+}+\mathrm{HCO}_{3}
$$

Furthermore, after encapsulation of BCA into the ZIF-8, considering that the BCA and ZIF- 8 have the same metal $\mathrm{Zn}$, the capture of $\mathrm{CO}_{2}$ was greatly increased. The yields of the solid $\mathrm{CaCO}_{3}$ obtained by using the BCA-ZIF-8 composite was determined to be $34.3 \mathrm{mg}$ of $\mathrm{CaCO}_{3}$ per $\mathrm{mg}$ of BCA compared to $29.5 \mathrm{mg}$ of $\mathrm{CaCO}_{3}$ per $\mathrm{mg}$ of free BCA. Additionally, due to the difficulty of recovery of the free enzyme, the encapsulated BCA could be more efficient in the conversion of $\mathrm{CO}_{2}$ into $\mathrm{CaCO}_{3}$ than free BCA. Therefore, the BCA-ZIF-8 composites could be successfully applied as an excellent accelerator for $\mathrm{CO}_{2}$ sequestration into $\mathrm{CaCO}_{3}$.

\section{Conclusions}

A facile and environmentally-friendly platform was successfully developed for the encapsulation of bovine carbonic anhydrase into the crystalline hybrid framework of ZIF-8. The microporous ZIF-8 material provided the best combination of pore size and high surface area for achieving high BCA loading and activity for the encapsulation of the enzymes. Among the different immobilization methods that have been introduced to date, it seems that the de novo approach is more adapted to BCA immobilization due to the suitable protection of the enzyme, avoidance of leaching, and making it possible for the entrapping of enzymes with larger dimensions than the pore size of the MOF.

The encapsulation of BCA into the ZIF-8 platform significantly increased the thermal stability, storage stability and the reusability of the enzyme. In particular, the rigid scaffold of the ZIF-8 increases the storage stability and also protected the embedded enzyme from deactivation. A storage stability test was conducted for up to 37 days and it was observed that the activity of the encapsulated BCA showed only a 10\% decrease compared to the free BCA which showed more than 50\% decrease in activity.

The $\mathrm{CO}_{2}$ sequestration capacity based on the conversion of $\mathrm{CO}_{2}$ to $\mathrm{CaCO}_{3}$ was also quantified. The $\mathrm{CO}_{2}$ sequestration capacity of BCA-ZIF-8 was determined to be $34.3 \mathrm{mg}$ of $\mathrm{CaCO}_{3}$ per $\mathrm{mg}$ of BCA compared to $29.5 \mathrm{mg}$ of $\mathrm{CaCO}_{3}$ per $\mathrm{mg}$ of BCA for free BCA. In particular, the activity of this robust bio-catalytic composite on the challenging $\mathrm{CO}_{2}$ sequestration led to excellent enzymatic performances even after 10 cycles. Therefore, the prepared biocatalyst can be applied for industrial applications. The present study paves the way to the use of the porous ZIF-8 material as a new host matrix to immobilize the BCA enzyme for preparation of a green, stable, reusable, and convenient biocatalyst for $\mathrm{CO}_{2}$ sequestration catalytic applications under mild conditions.

\section{Conflicts of interest}

There are no conflicts to declare.

\section{Acknowledgements}

We are grateful to the Iranian National Science Foundation (INSF) project number 96003992 and the Research Council of the University of Isfahan project number 1023 for financial support of this work.

\section{Notes and references}

1 K. Drauz, H. Gröger and O. May, Enzyme Catalysis in Organic Synthesis, 3 Volume Set, John Wiley \& Sons, 2012.

2 M. Kapoor and M. N. Gupta, Process Biochem., 2012, 47, 555569.

3 O. Kirk, T. V. Borchert and C. C. Fuglsang, Curr. Opin. Biotechnol., 2002, 13, 345-351.

4 U. T. Bornscheuer, G. W. Huisman, R. J. Kazlauskas, S. Lutz, J. C. Moore and K. Robins, Nature, 2012, 485, 185.

5 S. A. Montzka, E. J. Dlugokencky and J. H. Butler, Nature, 2011, 476, 43.

6 A. A. Olajire, Energy, 2010, 35, 2610-2628.

7 C. Forsyth, T. W. S. Yip and S. V. Patwardhan, Chem. Commun., 2013, 49, 3191-3193.

8 R. Barbero, L. Carnelli, A. Simon, A. Kao, A. d. A. Monforte, M. Riccò, D. Bianchi and A. Belcher, Energy Environ. Sci., 2013, 6, 660-674.

9 B. H. Jo, I. G. Kim, J. H. Seo, D. G. Kang and H. J. Cha, Appl. Environ. Microbiol., 2013, 79, 6697-6705.

10 V. M. Krishnamurthy, G. K. Kaufman, A. R. Urbach, I. Gitlin, K. L. Gudiksen, D. B. Weibel and G. M. Whitesides, Chem. Rev., 2008, 108, 946-1051.

11 H. Steiner, B.-H. Jonsson and S. Lindskog, Eur. J. Biochem., 1975, 59, 253-259. 
12 D. N. Silverman and S. Lindskog, Acc. Chem. Res., 1988, 21, 30-36.

13 R. DiCosimo, J. McAuliffe, A. J. Poulose and G. Bohlmann, Chem. Soc. Rev., 2013, 42, 6437-6474.

14 M. C. R. Franssen, P. Steunenberg, E. L. Scott, H. Zuilhof and J. P. M. Sanders, Chem. Soc. Rev., 2013, 42, 6491-6533.

15 J. M. Palomo, C. Ortiz, G. Fernández-Lorente, M. Fuentes, J. M. Guisán and R. Fernández-Lafuente, Enzyme Microb. Technol., 2005, 36, 447-454.

16 M. Hartmann and X. Kostrov, Chem. Soc. Rev., 2013, 42, 6277-6289.

17 S. Datta, L. R. Christena and Y. R. S. Rajaram, 3 Biotech, 2013, 3, 1-9.

18 R. Wang, Y. Zhang, D. Lu, J. Ge, Z. Liu and R. N. Zare, Wiley Interdiscip. Rev.: Nanomed. Nanobiotechnol., 2013, 5, 320328.

19 D. A. Cowan and R. Fernandez-Lafuente, Enzyme Microb. Technol., 2011, 49, 326-346.

20 P. Li, S.-Y. Moon, M. A. Guelta, L. Lin, D. A. Gómez-Gualdrón, R. Q. Snurr, S. P. Harvey, J. T. Hupp and O. K. Farha, ACS Nano, 2016, 10, 9174-9182.

21 O. Barbosa, C. Ortiz, Á. Berenguer-Murcia, R. Torres, R. C. Rodrigues and R. Fernandez-Lafuente, Biotechnol. $A d v .$, 2015, 33, 435-456.

22 S. Ding, A. A. Cargill, I. L. Medintz and J. C. Claussen, Curr. Opin. Biotechnol., 2015, 34, 242-250.

23 M. Sandor, A. Riechel, I. Kaplan and E. Mathiowitz, Biochim. Biophys. Acta, 2002, 1570, 63-74.

24 S. Wanjari, C. Prabhu, T. Satyanarayana, A. Vinu and S. Rayalu, Microporous Mesoporous Mater., 2012, 160, 151158.

25 M. Vinoba, K. S. Lim, S. H. Lee, S. K. Jeong and M. Alagar, Langmuir, 2011, 27, 6227-6234.

26 V. Lykourinou, Y. Chen, X. Sen Wang, L. Meng, T. Hoang, L. J. Ming, R. L. Musselman and S. Ma, J. Am. Chem. Soc., 2011, 133, 10382-10385.

27 E. Gkaniatsou, C. Sicard, R. Ricoux, J.-P. Mahy, N. Steunou and C. Serre, Mater. Horiz., 2017, 4, 55-63.

28 J. Juan-Alcañiz, J. Gascon and F. Kapteijn, J. Mater. Chem., 2012, 22, 10102-10118.

29 J. Cui, S. Ren, B. Sun and S. Jia, Coord. Chem. Rev., 2018, 370, 22-41.

30 Y. Feng, L. Zhong, M. Bilal, Z. Tan, Y. Hou, S. Jia and J. Cui, Polymers, 2019, 11, 27.

31 S. Tadepalli, J. Yim, S. Cao, Z. Wang, R. R. Naik and S. Singamaneni, Small, 2018, 14, 1702382.

32 J. Cui, Y. Feng, T. Lin, Z. Tan, C. Zhong and S. Jia, ACS Appl. Mater. Interfaces, 2017, 9, 10587-10594.
33 P. Li, S.-Y. Moon, M. A. Guelta, L. Lin, D. A. Gómez-Gualdrón, R. Q. Snurr, S. P. Harvey, J. T. Hupp and O. K. Farha, ACS Nano, 2016, 10, 9174-9182.

34 Y. Pocker and J. Stone, Biochemistry, 1967, 6, 668-678.

35 J. Kernohan, Biochim. Biophys. Acta, Enzymol. Biol. Oxid., 1965, 96, 304-317.

36 A. Phan, C. J. Doonan, F. J. Uribe-Romo, C. B. Knobler, M. O'keeffe and O. M. Yaghi, Acc. Chem. Res., 2010, 43, 58-67.

37 S. Wang, X. Li, H. Wu, Z. Tian, Q. Xin, G. He, D. Peng, S. Chen, Y. Yin, Z. Jiang and M. D. Guiver, Energy Environ. Sci., 2016, 9, 1863-1890.

38 J. Hou, G. Dong, B. Xiao, C. Malassigne and V. Chen, J. Mater. Chem. A, 2015, 3, 3332-3342.

39 S. Ren, Y. Feng, H. Wen, C. Li, B. Sun, J. Cui and S. Jia, Int. J. Biol. Macromol., 2018, 117, 189-198.

40 S. Zhang, M. Du, P. Shao, L. Wang, J. Ye, J. Chen and J. Chen, Environ. Sci. Technol., 2018, 52, 12708-12716.

41 S. Ren, C. Li, Z. Tan, Y. Hou, S. Jia and J. Cui, J. Agric. Food Chem., 2019, 67, 3372-3379.

42 M. Aggarwal, C. D. Boone, B. Kondeti and R. McKenna, J. Enzyme Inhib. Med. Chem., 2013, 28, 267-277.

43 R. G. Khalifah, J. Biol. Chem., 1971, 246, 2561-2573.

44 S. Rafiei, S. Tangestaninejad, P. Horcajada, M. Moghadam, V. Mirkhani, I. Mohammadpoor-Baltork, R. Kardanpour and F. Zadehahmadi, Chem. Eng. J., 2018, 334, 1233-1241.

45 M. M. Bradford, Anal. Biochem., 1976, 72, 248-254.

46 M. Aghababaie, M. Beheshti, A.-K. Bordbar and A. Razmjou, RSC Adv., 2018, 8, 4561-4570.

47 S. Zhang, Z. Zhang, Y. Lu, M. Rostam-Abadi and A. Jones, Bioresour. Technol., 2011, 102, 10194-10201.

48 U. K. Winkler and M. Stuckmann, J. Bacteriol., 1979, 138, 663-670.

49 M. He, J. Yao, Q. Liu, K. Wang, F. Chen and H. Wang, Microporous Mesoporous Mater., 2014, 184, 55-60.

50 Y. Pan, Y. Liu, G. Zeng, L. Zhao and Z. Lai, Chem. Commun., 2011, 47, 2071-2073.

51 K. S. Park, Z. Ni, A. P. Côté, J. Y. Choi, R. Huang, F. J. UribeRomo, H. K. Chae, M. O'Keeffe and O. M. Yaghi, Proc. Natl. Acad. Sci. U. S. A., 2006, 103, 10186-10191.

52 Y. Hu, H. Kazemian, S. Rohani, Y. Huang and Y. Song, Chem. Commun., 2011, 47, 12694-12696.

53 Q. Wang, X. Zhang, L. Huang, Z. Zhang and S. Dong, Angew. Chem., Int. Ed., 2017, 56, 16082-16085.

54 Y. Zhang, H. Wang, J. Liu, J. Hou and Y. Zhang, J. Mater. Chem. A, 2017, 5, 19954-19962.

55 T. L. Donaldson and Y. N. Nguyen, Ind. Eng. Chem. Fundam., 1980, 19, 260-266. 